\title{
CRIANÇA PESSOAL DE UM CASO OBLÍQUO: des-Colonização e Resistência na Escola
}

\author{
João Porto ${ }^{1}$ \\ Adriana Magro ${ }^{2}$ \\ Hiran Pinel ${ }^{3}$
}

Resumo: Atenta-se nesses escritos para descrições e levantamentos sobre como; transpassado por delimitações curriculares como a prescrição, o currículo oculto, o currículo nulo e outras conformações; a infância é colonizada instrumentalmente, no Sistema Escolar, e de qual maneira os pontos de resistência, docente e discente, podem contribuir com a des-Colonização das infâncias categorizadas ao longo do tempo, principalmente no que tange à apropriação religiosa.

Palavras-chave: Currículo; Resistência; Colonização Infantil.

\section{PERSONAL CHILD FROM AN OBJECTIVE CASE: decolonization and resistance in school}

\begin{abstract}
This study aims to set forth descriptions and surveys on how, surpassing through curricula boundaries as a prescription, the hidden curriculum, the null curriculum and other conformations; the childhood is settled instrumentally, in the School System, and in what way the endurance points, teacher and student, can add to the child decolonization sorted over time, particularly with regard to the religion ownership.
\end{abstract}

Keywords: Curriculum; Resistance; Child Colonization.

\section{Uma mesa posta}

Supondo uma mesa posta, coberta com todas as delícias que gostamos ou que odiamos, a visualizamos e, num ímpeto muito próprio ao humano, tendemos considerar "escolher" o que queremos comer dessa mesa. Todas as crianças na Escola parecem ter aprendido uma regra simples: existe uma prescrição do que "se precisa aprender", sem um anúncio claro e disponível sobre que, de fato, não é o que se precisa aprender, mas "o que alguém quer que se aprenda" e o "por que quer que se aprenda". Na Educação prescrevemos um currículo o qual será um mapa a ser seguido por uma horda de pequenos que, ao final, deverão responder "o que você vai ser quando crescer?", mesmo que esse currículo já produza uma resposta com esse diagnóstico. Sobre esses parâmetros, os descritivos, ignoramos que o currículo deveria ser uma extração e

\footnotetext{
${ }^{1}$ Professor de Ensino e Aprendizagem no Departamento de Linguagens, Cultura e Educação (DLCE) do Centro de Educação (CE) da Universidade Federal do Espírito Santo (UFES). Doutor em Educação e Práticas Educacionais Inclusivas pelo Programa de Pós-Graduação em Educação do Centro de Educação da Universidade Federal do Espírito Santo.

${ }^{2}$ Graduação em Educação Artística pela Universidade Estadual de Londrina (2002), mestrado em Educação pela Universidade do Oeste Paulista (2006) e doutorado em Educação pela Universidade Federal do Espírito Santo (2010). Atualmente é professor adjunto da Universidade Federal do Espírito Santo.

${ }^{3}$ Professor da UFES/CE/PPGE. Professor titular aposentado do DETEPE/ UFES/ CE. Leciona e pesquisa nos cursos de mestrado, doutorado, especialização, supervisão de pós-doutorado em Educação/ UFES. Pós-Doutorado em Educação pela FAE/UFMG - Área: Conhecimento e Inclusão Social; Pós-Doutorando (em curso) em Educação pela UFES/CE/PPGMPE.
} 
sistematização da vida para que, didaticamente, o mesmo fosse objeto de aprendizagem, escolarizado, para as crianças. Não perguntamos do que querem se servir ou o que querem aprender essas crianças, apenas oferecemos - e não se condena aqui o conteudismo - aquilo que o mundo historicamente já catalogou. "Ei, e a sobre a mesa posta?" Todas as crianças têm noção das coisas que gostariam de aprender, seus interesses, suas expectativas e, que fique claro, nada nos impede de oferecer mais, porém o que talvez ainda não compreendamos sobre currículo é que ele é aquilo que escolheram por nós. Vemos a mesa posta, nos empolgamos para ir à mesa escolher o brigadeiro, mas alguém só nos permite comer o bolinho de arroz. Igualmente, há quem goste de bolinho de arroz. Assim, o currículo é uma mesa posta ou, nesse caso, imposta, sobre a qual verificamos muitas possibilidades e, sem dúvida, as desejamos, porém alguém retira dela o que supõe "ter de ser" o alvo do nosso desejo e nos oferece, ou pior, nos obriga a comer. Bem-aventurados aqueles que gostam de bolinho de arroz e lhes é oferecido bolinho de arroz. Melhor ainda se pudessem provar também o brigadeiro e ter a chance de poder começar a gostar e provar de outras iguarias nessa farta mesa.

Nas condições modernas o currículo se tornou uma estruturação de poder e com uma forte tendência etnocêntrica. No caso de um Governo com bases neoliberais e fundamentalistas, o Currículo Prescrito é um instrumento eficaz para determinar não "aonde os sujeitos chegarão", mas "como eles chegarão". A máxima que traduz a descoberta dessa profanação do arbítrio é a de que "a mão que balança o berço, é a mão que controla o mundo". Assim, com uma definição empobrecida sobre o que deveria ser um Currículo Prescrito, os órgãos responsáveis pela Educação no Brasil, cedendo a investidas, por exemplo, do Banco Mundial, da $\mathrm{OCDE}^{4}$ e da recém-chegada ao poder, bancada Fundamentalista Cristã, viabilizou uma regulação para práticas de colonização da infância com o intuito de formar um cidadão que empreste crédito às suas propostas escusas.

Bases curriculares comuns chegam à Educação sem garantir direitos há muito conquistados - ou em processo de conquistas - de categorias antes invisibilizadas dentro das escolas. Dissolvemos pretos, bichas, gestantes, indígenas, pessoas com deficiências, lésbicas, mulheres, ateus, entre outros que necessitam ser nomeados nas

\footnotetext{
4 Organização para Cooperação e Desenvolvimento Econômico, formada por um bloco de países desenvolvidos que pretendem um mapeamento mundial nas áreas de Educação, Saúde e Desenvolvimento Humano, com vistas no colonialismo neoliberal. A partir de suas propostas de Avaliação Padronizada Internacional (PISA), interfere nos Currículos e Políticas Educacionais de países em desenvolvimento.
} 
leis, em termos curriculares genéricos do campo das matrizes culturais, das relações e da diversidade. Também, para além da pulverização das identidades na BNCC - Base Nacional Curricular Comum, aprovada para o Sistema Educacional Brasileiro (BRASIL, 2017), ainda servimos às crianças, dessa mesa, quitutes gourmetizados de embranquecimento, de macho-hetero-normativismo, de cristianismo, de europeísmo, de emburguesamento e, até, de uma beleza clássica divisora do bem e do mal. Essa é a estética curricular da mesa posta.

Ainda adentraram a essa mesa, nos últimos anos, o Decreto 7107/2010, num acordo explícito com o Vaticano, da obrigatoriedade de oferta nas escolas do Ensino Religioso Católico, remendado em 27 de Setembro de 2017 - dia dos santos infantes, Cosme e Damião -, com a aprovação do Supremo, de que o mesmo deva ser confessional, evidentemente cristão. Nas prescrições da BNCC, também se categorizou, em detrimento de outros saberes que foram condensados em grandes áreas, uma área exclusiva para o Ensino Religioso obrigatório na Educação Básica.

Mesmo fora da escola, socialmente, temos uma forte influência de Currículos Prescritos como os livros sagrados religiosos, os códigos civis, as constituições, as legislações, os jornais e revistas. Grandes listas de "o quê e como devemos ser". Afora isso - o que ousamos aqui chamar de Currículos Cíclicos - há uma repetição pelo docente do currículo fundamentado em uma cultura branca, num padrão heteronormativo, em uma sujeição ao potencialmente burguês e, muito comumente, ao controle cristão que já lhe fora imposto em sua saudosa "na minha época". É fato que, com exceção de poucos resistentes, o Currículo Prescrito e escolarizado pelo qual passamos, aquele imposto, com o qual somos servidos (ANYON, 1980), é repetido socialmente e também replicado com o nosso retorno, como professores, na escola. Acaba, esse currículo, por determinar o quê, onde e como chegamos à vida adulta. Em sua doutrina, nos tornamos aquilo que escolheram por nós. Dá-se, assim, a manutenção cíclica de um sistema alienante de colonização epistemológica tendo como colonizadas, as crianças na escola:

O currículo escolar ensina o cristianismo como única possibilidade - a criança é cristianizada - como adulto ela cristianiza outros discriminando a diversidade religiosa - o currículo social se retroalimenta com esses agentes que, na escola ensinam o cristianismo com única possibilidade - a criança é cristianizada - como adulto ela cristian...

O currículo escolar ensina a potência do homem sobre a mulher 
- a criança é machificizada - como adulto ela se mantém sexista, homofóbica, transfóbica, etc. - o currículo social se retroalimenta com esses agentes que, na escola, ensinam a potência do homem sobre a mulher - a criança é machificizada como adulto ela se mantém sexis...

Logo, comumente, encontramos negros com atitudes racistas, porque aprenderam, num currículo escolar, por doze anos, que no Brasil é mais vantajoso ser branco e ser visto como branco; mulheres com a subjetividade revolvida pelo machismo e sexismo, pelas vantagens e privilégios verificados em um currículo macho-hetero; religiosos com intolerância religiosa, porque lhes fora oferecido o etnocentrismo de um único deus possível, de uma única fé possível, com um único modo de vida viável e mais uma série de violentas colonizações infantis.

No sistema de Currículos Cíclicos, por exemplo, verificamos um empenho, no Brasil, de uma bancada fundamentalista cristã, em renegar as formas de aprendizagem pautadas nas ciências e que tenta implantar uma ordem curricular religiosa corrosiva à diversidade escolar e social. Há um discurso inflamado sobre que, por exemplo, a Educação Sexual é uma atribuição da família. Se repetimos um currículo pelo qual passamos, fica evidenciado, com esse discurso, que continuaremos com os mesmos desafios como gravidez na adolescência, suicídio por questões de identidade de gênero e sexualidade, machismo, violência, homofobia, lesbofobia, transfobia, mutilações, questões de saúde da ordem do aborto, das doenças sexualmente transmissíveis e, um dos piores, a regulação religiosa sobre os corpos. Essa atribuição dada à família poderia ter efeitos dentro de uma sociedade em que os pais já tivessem passado por um Currículo Sexual na escola, que já tivessem internalizado esses processos e os constituídos como cultura. Com uma educação efetiva e formativa, em alguns anos, de fato, não seria necessária a escolarização do Currículo Sexual, mas estamos a centenas de anos dessa possibilidade.

A maioria das intervenções fundamentalistas cristãs no Sistema Educacional Brasileiro vem pautada sob a forma de Currículo Oculto ou de Currículo Nulo. A despeito disso, deputados e senadores se empenham a todo custo, por exemplo, pela aprovação do Projeto de Lei 867/2015 que trata, incoerentemente, de uma escola sem doutrinação - a Escola Sem Partido - salvo se essa doutrinação for cristã. Nos primórdios de seus investimentos, os defensores desse projeto propunham como justificativa em seu site oficial escolasempartido.org (extrato do acesso no dia 19 de setembro de 2016): 
É fato notório que professores e autores de livros didáticos vêm-se utilizando de suas aulas e de suas obras para tentar obter a adesão dos estudantes a determinadas correntes políticas e ideológicas; e para fazer com que eles adotem padrões de julgamento e de conduta moral especialmente moral sexual - incompatíveis com os que lhes são ensinados por seus pais ou responsáveis. Note-se por fim, que o projeto não deixa de atender à especificidade das instituições confessionais e particulares cujas práticas educativas sejam orientadas por concepções, princípios e valores morais, às quais reconhece expressamente o direito de veicular e promover os princípios, valores e concepções que as definem, exigindo-se, apenas, a ciência e o consentimento expressos por parte dos pais ou responsáveis pelos estudantes. [grifos nossos]

Ocultam-se, nesse currículo, o interesse no controle dos corpos pela propagação de uma moral sexual e, sem neutralidade, priorizam-se os interesses, princípios, valores e concepções das escolas confessionais - apenas cristãs - anulando a discussão da laicidade em todas as instituições públicas no Brasil, inclusive a Escola. Tão recortadas e tão desuniformes são as leis no país que, mesmo diante da prerrogativa de um Estado laico, é reafirmado na forma legal de disciplina escolar Ensino Religioso, pela BNCC Base Nacional Curricular Comum -, na categoria não obrigatória para a adesão discente, porém com oferta obrigatória no currículo escolar. A proposta prossegue baseada no Art. 33 da Lei 9394/96 que trata das de Diretrizes e Bases da Educação.

Art. 33. O ensino religioso, de matrícula facultativa, é parte integrante da formação básica do cidadão e constitui disciplina dos horários normais das escolas públicas de ensino fundamental, assegurado o respeito à diversidade cultural religiosa do Brasil, vedadas quaisquer formas de proselitismo.

Voltando-nos à forte tendência de uma colonização da infância pelo currículo, colocamos aqui uma descrição de experiências do vivido e instrumentos curriculares, analisando um recorte específico, porém ínfimo, do maximizado imperialismo religioso dentro do contexto escolar. Conceberemos os atravessamentos inevitáveis e variáveis entre o Currículo Prescrito - social e escolar -, o Currículo Vivido, que é invisibilizado pela perpetuação do tradicionalismo, o Currículo Oculto, considerado não-prescrito, que tem ensinamentos implícitos, porém uma aprendizagem explícita e o Currículo Nulo, aquele que é anulado para não ser aprendido e nem prescrito.

\section{Justificativa, métodos e objetivos}

A partir das prerrogativas apresentadas, entendemos que são justificadas as 
tentativas de se elucidar como se dão os processos de colonização e, mesmo, desColonização ${ }^{5}$ da infância no contexto escolar. Ainda mais pautado numa era de desqualificação da Escola para a qualificação de um pensamento fundamentalista cristão como modos de controle e regulação dos corpos.

Escrever, então, se torna um desafio, dado ao incômodo controle sobre a indignação com situações-problema que poderiam ser sanados se o próprio currículo, pelo qual passamos, não nos impusesse regular os descontentamentos na escrita. Porém, ao nos aproximarmos de um método fenomenológico, com obviedade qualitativa, conseguimos nos propor a uma metodologia de narrativa-mergulho, para uma emersãocrítica do fenômeno vivido-e-ou-observado, o que se dará nesses escritos por meios que em algum momento se aproximam do literário e pela descrição de fatos vividos dentro de contextos escolares. Uma vertente que se aproxima do que Barbara Christian, citada por Sandoval (2000), em Methodology of the Opressed, escreve:

My 'method' is not fixed... it is based on what I read and how it affects me, that is, on the surprise that comes from reading something that compels you to read differently.... I therefore have no method, since every work suggests a new approach.

O meu 'método' não é fixo... É baseado no que eu li e como o que eu li me afeta, isto é, na surpresa que vem de ler algo que te obriga a ler de maneira diferente... Portanto, eu não tenho método, uma vez que cada trabalho sugere uma nova abordagem.

Entretanto, é suposto que nenhuma fala é encerrada em despropósito, que sempre se objetiva alguma coisa (FOUCAULT, 1996) quando de alguma incisão discursiva. Então seria ideal que, ao lermos esses escritos, pudéssemos verificar que foi alcançado o objetivo de se ter uma descrição de como a colonização da infância se dá, oficial e extra-oficialmente, por meio da manipulação dos modos curriculares vigentes, bem como da influência dos mesmos na contra-produção que aqui chamamos de resistência para a des-Colonização da infância no ambiente escolar.

\section{A escola-sitiada e colonização da/na infância}

Desde que Ariès (1979) nos indica o conturbado surgimento do conceito de

\footnotetext{
5 Decidimos pela utilização do termo com essa formatação, pois cremos que a discussão da descolonização é mais ampla e que ainda precisamos avaliar se a mesma, de fato, existe. Também, para esses escritos, cremos que não parece que, com a descolonização, haverá um livramento de quaisquer outras colonizações e, logo, para efeito de emancipação e libertação no conhecimento do conceito de descolonização, será inevitável que sempre exista uma colonização.
} 
Infância, estamos propensos em acreditar, na era contemporânea, numa Infância dos Sujeitos de Direito. A evidência, pelos dados estatísticos sobre o trabalho infantil, sobre a violência contra crianças, bem como sobre o acesso às escolas, deixa nítida a ideia de que a Infância Negada e a Infância Institucionalizada coexistem e perambulam, simultaneamente, com a garantia de direito às crianças.

Com o surgimento da ideia capitalista de família - loteada, na atualidade, com o conceito cristão na composição heteronormativa de um casal com filhos consanguíneos -, surge também a ideia de "qualificação" dessa família com o surgimento da instituição escola. A produtora de adultos surge dentro de um patamar de exclusão, normativismo, divisão de classes sociais e de concepção de uma Infância Institucionalizada onde o infante passa a ser considerado, além de filho, aluno. A escola, portanto, atende aos preceitos de regulação moral, de controle do capital, sexual e de corpos e, vindo de uma era imprópria de Infância Negada, corrobora com a ideia de reclusão, transformação e preparação do sujeito para uma vida adulta. Assim, o ocidente entrega suas crianças à preparação para "ajuntamento" financeiro na escola. Para tanto é necessário "moldar" às crianças ao tipo ideal social que responda às demandas fundamentalistas e capitalistas.

As vertentes de escolarização dos saberes, até então dominados pela igreja, já precedem uma escola que transpõe os quesitos de ciência e corrobora com uma "igrejização" do currículo escolar. A escola é então sitiada pelo pensamento conventual, inclusive arquitetonicamente, e não tão mais tarde acrescida (FOUCAULT, 1987) da condição prisional e sanatorial.

Assim os currículos supostos atravessaram séculos de uma regulação dos corpos infantis nas classes escolares e, os mesmos, usaram vários modos de colonização com objetivos de controle e alienação. A escola se vê sitiada e atendendo a demandas que, hoje, deveriam ser atribuídas a outras instituições. Mesmo sendo uma das últimas, vindo bem depois da medicina, da igreja e da família, a escola da atualidade acaba assumindo papéis que se desviam totalmente dos eixos pedagógicos. Infelizmente, a escola se tornou um instrumento de regulação, inclusive para outras instituições.

\section{A colonização religiosa na escola}

Segundo Silva (2015) o Currículo Oculto não consiste exatamente numa teoria. O Currículo Oculto, dentro de uma perspectiva Crítica, atende aos quesitos de entendimento da ideologia e dos aparelhos ideológicos que se expressam mais "através 
de rituais, gestos e práticas corporais do que através de manifestações verbais." (SILVA, 2015, p. 77). Nos parece, com respeito ao pensamento do autor que, relações de autoridade, características estruturais da sala de aula, a organização espacial, a distribuição do tempo, os padrões de recompensa, entre outros, formam um escopo de ensinamento sutil para uma aprendizagem eficaz daquilo que se pretende sobre a formação do outro.

Compreendemos, dessa maneira, que o Currículo Oculto produz certo tipo de "naturalização" dos sentidos, sendo o do olhar o mais complexo que faz com que as crianças, dentro do Sistema Escolar, se adequem ao sujeito-produzido que corresponderá às possibilidades futuras de dominação, ora imposta pelo Governo, ora pela Igreja, ora pela acomodação à falta de Justiça Social, ora pelo Mercado e por muitos outros ou mesmo pelo conjunto coorporativo entre todos eles.

Especificamente, nesse recorte, sobre a colonização religiosa da criança no ambiente escolar e pensando numa perspectiva de "currículos", a mesma conduz a uma intervenção repressora quanto a questões contundentes de identidade, de autonomia e de emancipação. Por vezes nos deparamos em um ambiente escolar que, por exemplo, constrói a ideia da universalidade da oração do Pai Nosso. São silenciados os discursos sem a compreensão que essa pseudo-universalidade é reduzida ao escopo das religiões cristãs. O mantra é repetido tantas vezes até a crença de que o "Pai é", de fato, "Nosso" e que todos somos cristãos. "Uma verdade" repetida tantas vezes a ponto de ser considerada uma "a única verdade".

Diversas incursões curriculares delimitam o percurso colonizador das infâncias e podem ser tomadas como exemplificação do que acontece com a colonização cristã. La Fontaine nos traz, por exemplo, a história difundida entre as crianças sobre a Formiga e a Cigarra. Os valores da bondade, da retidão e do trabalho são atribuídos à formiga que, destarte, representa o ideal curricular do operário dentro de uma dimensão laboral capitalista, ela corresponde aos ideais das divisões de classe e de territorialização entre proletário e patrão. Em contrapartida limita a "artista" Cigarra ao patamar da "vadiagem", da procrastinação, do ócio como maléfico e das artes, por exemplo, como não-essenciais à formação cidadã. Ousa ainda, a Cigarra, em perguntar "por que e para quem trabalhar tanto?’. E não ocultamente, o próprio Currículo Prescrito hierarquiza os saberes atribuídos às nossas personagens. Importancializa-se as ciências exatas, dentro da organização curricular, como propensões ao trabalho e desqualifica-se as ciências humanas como promotoras de emancipação financeira. No bojo desse currículo, nítida às crianças, está a 
arquitetura formativa de uma quantidade elevada na oferta do ensino da matemática desequalizada aos meros cinquenta minutos de uma aula de artes em uma mesma semana.

Desde cedo a subserviência e a alienação como respostas cegas para a cristianização e a padronização de uma moral sobre corpos, sobre as falas e sobre as identidades, também desembocam no currículo colonizador. Tomemos a seguinte canção, muito comumente usada nas séries inicias em escolas públicas e privadas:

\section{Carneirinho, carneirão, neirão, neirão \\ Olhai pro céu, olhai pro chão, pro chão pro chão, \\ Nosso Senhor mandou dizer, dizer, dizer, \\ Para todos se sentarem, \\ Para todos se levantarem, \\ Para todos se calarem, \\ Para todos ajoelharem...}

Mesmo com uma leitura parcial de decodificação de signos, longe dos letramentos possíveis para os significados semióticos aplicáveis, é possível verificar que, com esse tipo de instrumento, o Currículo Oculto ensina de forma sutil e contundente o silenciamento da infância, o condicionamento à religiosidade por imposição e a produção da resposta à pergunta: “o que você vai ser quando crescer?”. Serei um profissional obediente, não questionador e submisso às opressões patronais, religiosas, sociais, políticas, morais, entre tantas outras. A escola, atrelada ao serviço de catequização, punição e cura (FOUCAULT, 1987) traz em seus dogmas uma docilização dos corpos, um exercício de controle que ultrapassa tempo/espaço reverberando em bloqueios às identidades, às outras formas de religiosidade, às tantas outras sexualidades, silenciamentos políticos, epistemológicos e outros ecos.

Dentro de processos de colonização curricular, ainda produzimos atravessamentos como indicados por Boaventura de Sousa Santos e Paula Meneses (2010) que ultrapassam as fronteiras de um norte e sul globais. Fabens é uma cidade do Texas, Estados Unidos, situada à divisa de Ciudad Juárez, México. Um professor brasileiro entra na sala em seu primeiro dia de aula - estando apenas há dois meses na região -, senta-se, todos os olhares se voltam para ele. Durante o acolhimento e apresentações devidas, verifica em cima das mesas dos alunos, junto às lancheiras, sacolinhas transparentes com fichas bem maiores que moedas de um real, todas muito finas e coloridas. De tempos em tempos os alunos comem as fichas e se mantêm em silêncio na sala de aula. As fichas são hóstias ${ }^{6}$, que de uma maneira lúdica são coloridas

\footnotetext{
${ }^{6}$ Pães consagrados pela religião católica, prensados em formato circular com três centímetros de
} 
e viram uma brincadeira de silêncio e respeito.

FIGURA 1 - Hóstias coloridas

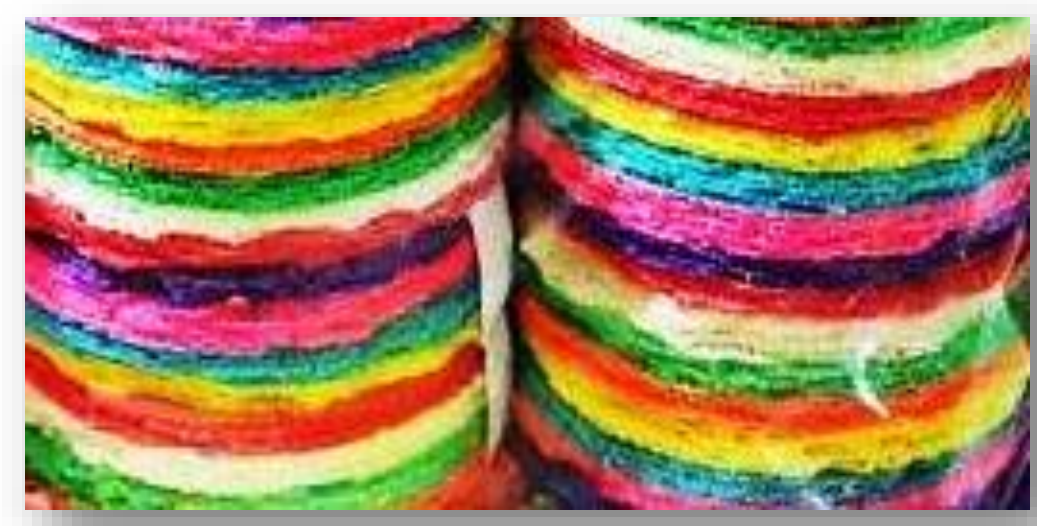

Fonte: Acervo pessoal. El Passo, Texas, 2012

A ludicidade é utilizada como instrumento de regulação, nos moldes religiosos, com uma contração da catequização em espaços públicos escolares. A brincadeira acaba por catolicizar os alunos de uma maneira que parece um tanto sutil. Em contraponto, porém não se livrando da alienação curricular nem da teocolonização, escondidas em suas lancheiras, os alunos traziam hóstias recheadas com doce de leite. Essa pequena prática, talvez intuitiva, nos remete a uma resistência ao que Boaventura de Sousa Santos (2010) poderia considerar como uma "dominação cada vez mais polifacetada", porém carecida de atenção, pois pode dificultar a identificação de quem domina e de quem é dominado, significando, muitas vezes, uma luta contra nós próprios. Pode se atrelar a uma ressignificação do domínio, ou não, daí a importância de consciência nos processos emancipatórios.

FIGURA 2 - Hóstias recheadas com "dulce de leche"

diâmetro e 0,6 g. Utilizados na Liturgia. Representam o corpo de Cristo. 


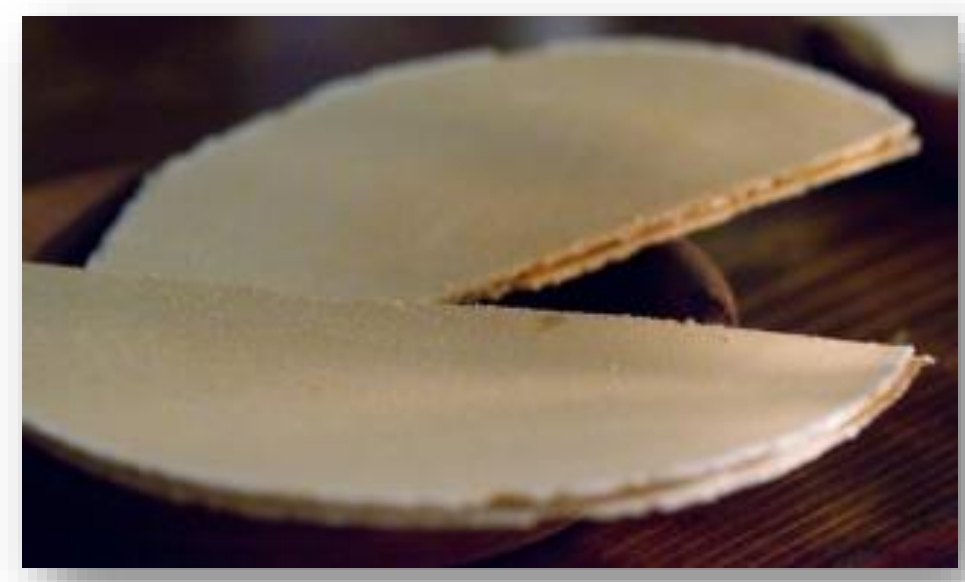

Fonte: https://www.recetascomidas.com/receta/obleas-dulces

Também, os instrumentos curriculares imagéticos, tais como dados aos descréditos de uma alfabetização visual, contribuem na proposição de uma colonização religiosa dentro dos muros da escola. Vejamos a planta baixa da igreja de Santiago de Compostela (1075 a 1128), um padrão adotado por muitos séculos desde o período Românico, atravessando os períodos Gótico, Renascentista e Barroco, servindo como base atual da arquitetura católica contemporânea.

FIGURA 3 - Reprodução da Planta da Igreja de Santiago de Compostela 


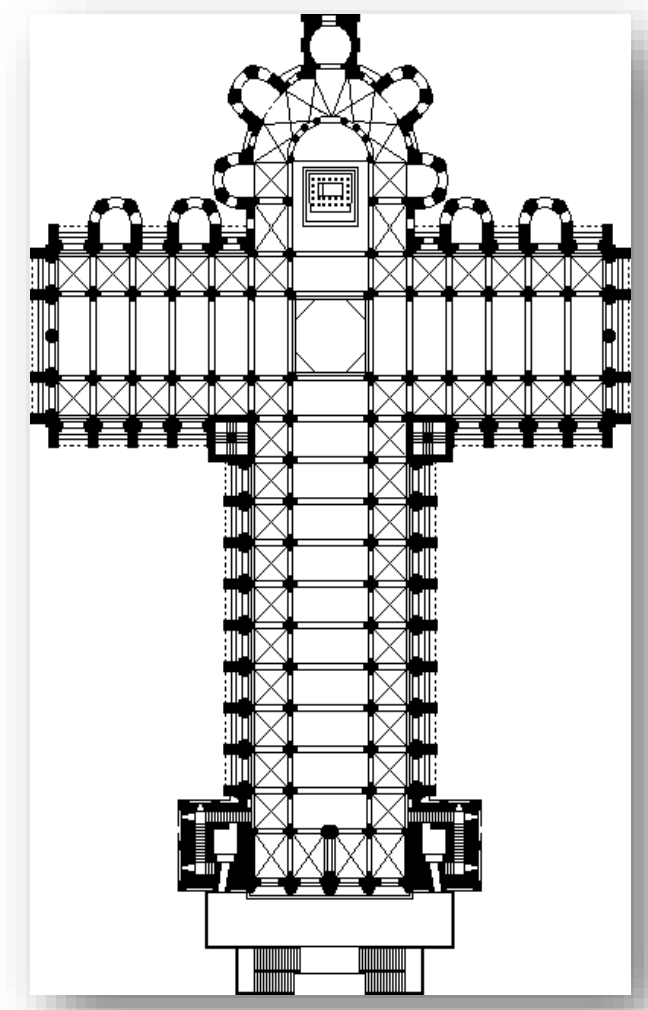

A parte superior (abóboda) da planta é a chamada de Abside. Para ela se direcionam todos os olhares atentos dos fiéis. É o lugar do alto clero, bem como do corpo e do sangue de Cristo. O lugar onde Deus visita os homens. O céu na terra. $\mathrm{O}$ Santíssimo. Descendo a planta, contemplamos a Nave Central, cortada por um Transepto que remete ao ícone principal cristão: a cruz. A base da planta é a entrada principal. Chegar à Abside era uma aproximação do céu, uma aproximação a Deus. Porém poucos conseguiam um lugar à frente na igreja. As cadeiras mais próximas ao santíssimo eram reservadas aos ricos e suas gordas fortunas garantiam um sepultamento próximo aos santos, embaixo do altar. Quanto mais dinheiro você tinha, mais avançava na nave principal rumo ao céu.

O currículo da colonização da infância, na escola, é constituído por práticas antigas com propósitos revisitados, reformulados e readequados às relações de ensino e aprendizagem. Nem sempre existe um propósito obscuro em tudo. Porém, um currículo pode atravessar centenas de anos em suas proposições, mesmo que haja superação nessas propostas. Vejamos a coincidência de uma brincadeira infantil presente na escola.

FIGURA 4 - Comparativo entre uma amarelinha e a Planta da Igreja de Santiago de Compostela 

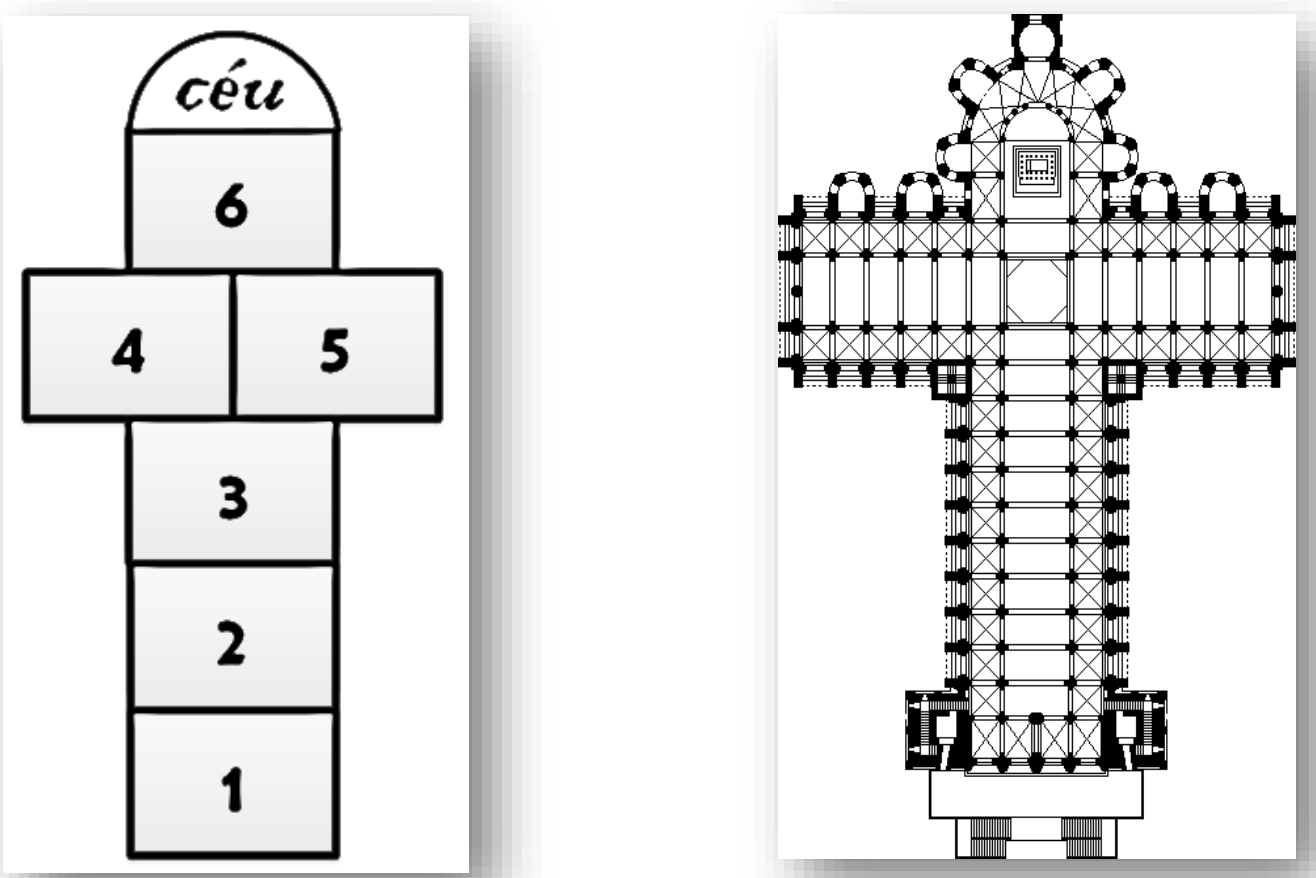

Algumas lendas dizem que o jogo da amarelinha foi resgatado pelos franceses de jogos da antiga Roma que representavam o percurso de vida. Ela chega ao Brasil com os Jesuítas e recebe esse nome pela aproximação fonética com o nome em francês "la merelle". Cabe ao jogador se empenhar em lançar uma "malha" até acertar os números de maneira cumulativa e quantitativa-crescente, conseguindo chegar ao "céu", se sagrando vencedor.

Dentro de uma perspectiva muito própria à escolarização, nos deparamos com a determinação de funções colonizadoras para a imagem, para a música, para a poesia, para arquitetura, para os saberes escolarizados, de uma maneira geral. Não raras vezes, essas funções são absorvidas pela intenção religiosa, no nível escolar. Dessa constatação não se pode afirmar que a colonização do olhar se dá em níveis generalizados e com equilíbrio de proporção. Algumas crianças podem ser afetadas de maneiras diferentes, porém dentro dos processos socioculturais, uma construção coletiva da subjetividade pode gerar pareamento no poder colonizador que essas categorias exercem desde épocas remotas. A imagem e as brincadeiras, por exemplo, são sedutoras. A representação imagética, os jogos e brincadeiras infantis, se utilizadas sem leituras objetivas e subjetivas, acabam por se posicionar no nível da naturalização e, tudo que é naturalizado, corrobora nas produções de cultura, aproximando o currículo dos modos de colonização do olhar, dos corpos, das leituras e das subjetividades das 
crianças na escola.

\section{Criança pessoal de um caso oblíquo}

Posta, a obrigatoriedade da oferta de Ensino Religioso no currículo escolar com indicações de confessionalismo cristão -, indicada numa Base Nacional Comum Curricular como instrumento de controle/descontrole do "pretenso" cidadão idealizado e com uma alegação sombria de direito e de igualdade, nos urgencia a pensar em alguns aspectos da subjetividade dos invisibilizados - as crianças. Nesse campo de disputas políticas e ideológicas, tendo uma escuta sensível, é possível aprender de seus meios de resistência produzidos para superar a colonização da religiosidade ou a falta de consideração com a mesma. Em alguns casos, como num ritual antropofágico, talvez as crianças possam regurgitar a colonização religiosa como modos de resiliência, resistência e artifícios atenuadores para as relações de ensino e aprendizagem na escola.

Antes de descrevermos um episódio em uma sala comum dentro de uma escola de Ensino Fundamental do Munícipio da Serra, no Estado do Espírito Santo, acataremos, segundo Porto (2019) que, dentre os inúmeros conceitos de subjetividade, talvez devamos considerar a subjetividade do homem como um conjunto de todas as suas expressões. Elas são muitas vezes aparentes, quase sempre visíveis, o que se detecta como um diagnóstico cultural dos sujeitos. Basicamente, a subjetividade se apresenta como uma externalização dos nossos comportamentos com os atravessamentos sociais. Entretanto, nesse conjunto, nossos sentimentos também perambulam pela nossa subjetividade. E como "pequenos príncipes" até nos atrevemos em nos aproximar do que Saint-Exupery (2005) alegava, sobre que o essencial é invisível aos olhos. A subjetividade posiciona-se, então, como um outing do nosso próprio "invisível”.

A subjetividade diz da nossa singularidade por sermos o que nós somos, mesmo atravessados por outros, diz também da condição humana genérica de sermos todos assim. Em síntese, a subjetividade é o nosso "religare" entre o material e o imaterial, é o homem em sua forma corpórea, mas também em sua forma pensamento, o homem em sua afetação, em seu afeto-ação.

Assim, a escola não parece carecer da religião. Subjetivamente, cada estudante apresenta-se com suas crenças e fé. A religiosidade pode partir de um campo pessoal e subjetivo para produzir resistências ao proposto/imposto. Vemos, no embate político 
pelo domínio do currículo, que ele é controle, e controle, inevitavelmente, é poder. Revel, quando em 2005, reapresenta-nos Foucault, diz que "na medida em que as relações de poder estão em todo lugar, a resistência é a possibilidade de criar espaços de lutas e agenciar possibilidades de transformação em toda parte” (p. 74).

Dessa maneira, ler subjetiva e objetivamente os currículos escolares, pode produzir resistência ao poder curricular-verticalizado que adentra à escola, também compreendendo que essa mesma resistência agencia possibilidades de transformação e, sendo a Educação priorado de uma transformação dialógica entre professores e alunos, isso poderia resultar numa des-Colonização das infâncias e, quem sabe, dos professores.

\section{des-Colonização e Resistência na Escola}

Sobre o ofício de professor é sabido de uma aprendizagem continuada durante o exercício da docência. Tal qual o aluno - e não, não acreditamos aqui no termo "sem-luz" associado a essa designação - o professor está imbricado nos processos de colonização da infância na escola, bem como na sujeição a um currículo inflexível, na maioria das vezes. Também é muito tênue a linha que divide uma posição anti-alienadora do professor de uma proposição etnocêntrica da contrafé. Para qualificar a emancipação, parece ser então, necessária, a desqualificação da subjetividade do outro. O jogo relacional opressoroprimido acaba por confundir-se quando da transformação da flexibilização curricular em modelo, tornando-a assim, tão ou mais opressora do que o currículo inflexível. Porém, também é conhecido, sobre esse ofício, que aprendemos muito dos alunos e de suas resistências e que, as mesmas, nos atravessam como formação, e assim os processos de "repetição do currículo pelo qual passamos" vão encontrando fragilidades e rupturas próprias de uma educação pautada numa aprender a aprender.

Enfim, sobre uma criança des-Colonizadora de currículos opressivos e como um "oblíquo de resiliências possíveis", se trata a narrativa que segue:

"Dia desses, nesses comuns, muito comuns mesmo, na escola, alunos fazendo algum exercício, me viro e vejo um desavisado de oito aninhos, em pé, falando baixo e gesticulando exaustivamente virado para a parede. "Bora trabalhar moleque?" Educadamente, trajado em suas calças de tecido-não-jeans, sua camisa branca de botões dois números acima e um chinelinho azul da cor dos seus olhos, ele dá um pausa e fala "só um minutinho tio" e volta a conversar com a parede. "Tudo bem, mas com quem você tanto conversa? Vai atrasar seu exercício." Evidente que eu 
já esperava alguma resposta surpreendente. "Peraí fessô, tô falando com Deus!" Olhei para a turma, que continuava o exercício, e ele prosseguiu. "Tô perguntando a ele isso mesmo: como fazer meu dever". Com todo espírito escolar, repressor, curricular e classificador eu já tinha formulado na minha cabeça algo como "aff, mais um esquizofrênico"; mas a escola também serve para os professores aprenderem. Contive a vontade de rir e disse "pede um tempinho pra Ele, faz seu exercício, depois vocês voltam a conversar." Depois de murmúrios acelerados ele volta a sentar-se diante do vazio do seu papel. A fé não é uma exclusividade da religião, nem ao menos do Deus Cristão. De fato, acho que os homens inventaram a fé e, talvez, quem sabe, Deus ou os deuses, para dar sentindo à nossa miserável estadia nesse planeta, no caso dele, na escola. Nesse dia - o do diálogo do aluno fiel -, fiquei pensando que a vida dói, assim como ensinar e aprender é dolorido e subjetivo. A dor de reconhecer uma vida efêmera com incertezas sobre o futuro, seja ele o da aprendizagem, talvez seja mais suportável quando temos fé em alguma coisa. Coisas que não vemos, mas pelas quais produzimos o desejo de que existam, de que darão certo. Talvez já tenham chamado isso de ideologia, utopia ou religião, vá lá entender a cabeça dos filósofos! Enfim, onde eu entrava como educador para reduzir a dor de aprender desse menino que enxergava apenas uma saída: 'perguntar a Deus'? Por que a Escola está tão distante de entender e aceitar as diferenças de fé que proliferam nesse espaço? Por que educadores se incomodam tanto com a crença dos alunos? Por que alguns educadores associam laicidade à descrença? Por que eu me descuidei daquele aluno? Evidente que depois de uma série de perguntas, incrédulos leitores acham que, na sequência, um soberbo professor daria repostas. Lógico que não temos respostas para essas coisas, mas não significa que não devamos acreditar e buscar essas respostas. Sentei-me ao lado do "moleque" e olhamos JUNTOS para seu papel em branco. Nossa existência estava ali. Narrei uma paisagem, tão fantasiosa, talvez, quanto uma parábola. Perguntei se queria desenhar aquelas palavras, ele prontamente disse que sim. Soube das dificuldades que ele tinha de fazer linhas inclinadas, guiei sua mão no preenchimento do seu vazio e ele guiou minha formação profissional, no preenchimento do meu vazio. Parece piegas, mas a fé dele produziu respostas. Meu discurso mudou um pouco sobre o radicalismo de uma escola laica. Não dá para a Educação menosprezar a contrarrazão, a crença dos alunos, sua fé. Escola laica não é uma escola sem fé. Afinal, as escolas se aproximaram em sua constituição espaço-tempo de um céu-inferno, de uma culpa-perdão, tudo muito religioso, tudo relacionado a crer... Espelhamo-nos na fé e agora queremos negá-la."”

A criança em seus modos subjetivos de resistência, na contramão de um currículo imposto e, a guisa das diversidades de uma sala de aula, cria um deus na parede e usa os mesmos artifícios, próprios de um currículo colonizador de infâncias, para refutar a não presença pedagógica do professor em seus desafios. De uma maneira resiliente, a criança - que a nosso ver compreendeu os instrumentos do currículo -

\footnotetext{
${ }^{7}$ Experiência de um professor de Artes no Ensino Fundamental 1, na cidade de Serra, Espírito Santo. O aluno, na época, frequentava a $4^{a}$ Série $\left(5^{\circ}\right.$ ano) e continuou na escola. Hoje ele está terminando o Ensino Fundamental 2 e há cerca de dois anos, numa visita feita à escola, relatou que quer ser professor ou dentista.
} 
utiliza-se dos mesmos para, inteligentemente, cobrar um direito: estou aqui para aprender e, se é o seu currículo que eu tenho que aprender, é seu dever me ensinar. Aqui também se supõe que ele recorre ao Deus cristão, mas quais garantias dessa suposição? Falar com deus é um pressuposto da criação dos mesmos, em e para qualquer crença. Seria muito bom imaginar que a percepção da criança a fizesse criar um deus que correspondesse suas expectativas quanto à ação docente.

"Depois de murmúrios acelerados ele volta a sentar-se diante do vazio do seu papel" narra o professor, aqui, o início da quebra protocolar de um currículo, qual seja o reconhecimento de que tanto a "religiosa culpa" quanto "a não aprendizagem" acabam, dentro dos processos de colonização, depositadas no sujeito e não nos responsáveis por ele. No papel vazio ele alerta: "nossa existência estava ali”. A subjetividade então se desnuda e o currículo volta ao teor humanizado do vivido. A partir do nada, da neutralidade, do zero, começa sua mútua aprendizagem, trazendo à tona um currículo horizontalizado, sem hierarquia e, longe da salvação individual cristã, um currículo colaborativo ao invés de competitivo.

\section{O que você vai ser quando crescer ou considerações finais}

A escola se apresenta com uma gama de possibilidades sobre a constituição dos sujeitos e, a partir delas, se enredou por uma dureza de currículo que, não compreendido - ou compreendido para propósitos colonizadores -, é utilizado na reprodução de um sistema de poder. Esse sistema de poder pode ser inflexível; pode ser oculto nos modos de ensinar, porém efetivo nos modos de aprender; pode ser anulado diante das possibilidades rizomáticas dos saberes; pode ser apenas uma prescrição da vida e, nos parece, que a única coisa que não tem sido é uma apropriação do vivido como garantia de emancipação das crianças.

Mesmo sendo concomitantes com uma Infância de Direitos, ainda somos subjugados, com a desculpa da Infância Institucionalizada da criança-filho-aluno, vazia em si e alvo para ideologias religiosas e fundamentalistas, entre outras, com vistas à alienação e a produção de adultos vulneráveis à dominação num regime opressor/oprimido. Ainda, nessa concomitância e, na pior colocação, a Infância de Direitos bebe na mesma taça amarga de uma Infância Negada que representa o hades da colonização infantil. Nessa organizada manutenção cíclica de um currículo colonizador, mesmo já tendo produzido subjetivamente, nas crianças, a resposta, ousamos perguntar: 
"o que você vai ser quando crescer?"

A despeito da colonização infantil a criança já “é”, naquele exato momento em que a questionamos. Há existências e resistências naquele sujeito. Há um currículo contínuo com base numa subjetividade individual e socialmente constituída. Desconsideramos sua existência e, sim, a escola contribui com isso. Porém a escola não se resume às paredes recheadas de contenções, moralismos-extremistas e personificações do mal. A ausência ou a contaminação fundamentalista de políticas específicas para a Educação tornam a escola um lugar que pode ser de colonização ou de resistência, dependendo da sua resposta de "qual adulto você ia querer ser".

É necessário um empenho militante e ativista, fortes, para uma des-Colonização da infância dentro dos contextos escolares - com uma reverberação para fora deles. Urge uma necessidade de projeção das identidades, religiosidades-outras e até, não religiosidades, dentro de um currículo que ainda é adubado com um cristianismo equivocado, um branquismo de privilégios, uma domesticação dos corpos.

"Peraí fessô, to falando com Deus! Tô perguntando a ele isso mesmo: como fazer meu dever?" Muitas crianças já conhecem os caminhos da resistência, precisam de ajuda para reelaborá-los colaborativamente, assim como professores precisam de ajuda para apropriarem-se, horizontalmente, desses modos de (r)existir. O que nos tornaram? Podemos alterar isso? O que nós somos agora que crescemos?

$$
\text { Recebido em: 27-02-2019 Aceito em: 11-03-2019 }
$$

\section{Referências}

ARIÈS, Philippe. A História Social da Infância e da Família. Rio de Janeiro: Zahar, 1979 .

ANYON, Jean. Social Class and the Hidden Curriculum of Work. Journal of Education, v. 162, n. 1, Fall 1980. Disponível em http:// cuip. uchicago. edu / cac/nlu/fnd504/ anyon. htm. Acesso em: 22/10/2012.

BRASIL. Constituição 1988. Constituição da República Federativa do Brasil. Brasília, DF: Senado Federal, 1988.

BRASIL. Ministério da Educação. Base Nacional Comum Curricular - BNCC. Brasília, DF: 2017.

FOUCAULT, Michel. A Ordem do Discurso. São Paulo: Edições Loyola, 1996. 
FOUCAULT, Michel. Vigiar e Punir. Petrópolis: Vozes, 1987.

PORTO, João. "PERAÍ FESSÔ, TO FALANDO COM DEUS!”: subjetividade como resistência na escola. LELLIS, Nelson; PINEL, Hiran (Org.). Religião, políticas e subjetividade. Rio de Janeiro: Terceira Via, 2018. No prelo.

REVEL, Judith. Michel Foucault: conceitos essenciais. Tradução de Carlos Piovezani Filho e Nilton Milanez. São Carlos: Claraluz, 2005.

SANDOVAL, Chela. Methodology of the Opressed. Minneapolis: University of Minnesota Press, 2000.

SANTOS, Boaventura de S.; MENESES, M. P. Epistemologias do Sul. São Paulo: Cortez, 2010.

SILVA, Tomaz Tadeu da. Documentos de Identidade: uma introdução às teorias do currículo. Belo Horizonte: Autêntica, 2015. 